\title{
Role of botulinum neurotoxin-A in cerebral revascularization graft vasospasm prevention: current state of knowledge
}

\author{
Kristine Ravina, MD, ${ }^{1}$ Ben A. Strickland, MD, ${ }^{2}$ Robert C. Rennert, MD, ${ }^{4}$ Joseph N. Carey, MD, ${ }^{3}$ and \\ Jonathan J. Russin, MD ${ }^{1,2}$
}

${ }^{1}$ Neurorestoration Center, ${ }^{2}$ Department of Neurological Surgery, and ${ }^{3}$ Division of Plastic and Reconstructive Surgery, Department of Surgery, Keck School of Medicine, University of Southern California, Los Angeles; and ${ }^{4}$ Department of Neurosurgery, University of California, San Diego, California

\begin{abstract}
Graft stenosis and occlusion remain formidable complications in cerebral revascularization procedures, which can lead to significant morbidity and mortality. Graft vasospasm can result in early postoperative graft stenosis and occlusion and is believed to be at least partially mediated through adrenergic pathways. Despite various published treatment protocols, there is no single effective spasmolytic agent. Multiple factors, including anatomical and physiological variability in revascularization conduits, patient age, and comorbidities, have been associated with graft vasospasm pathogenesis and response to spasmolytics. The ideal spasmolytic agent thus likely needs to target multiple pathways to exert a generalizable therapeutic effect. Botulinum toxin (BTX)-A is a powerful neurotoxin widely used in clinical practice for the treatment of a variety of spastic conditions. Although its commonly described paradigm of cholinergic neural transmission blockade has been widely accepted, evidence for other mechanisms of action including inhibition of adrenergic transmission have been described in animal studies. Recently, the first pilot study demonstrating clinical use of BTX-A for cerebral revascularization graft spasm prevention has been reported. In this review, the mechanistic basis and potential future clinical role of BTX-A in graft vasospasm prevention is discussed.
\end{abstract}

https://thejns.org/doi/abs/10.3171/2018.11.FOCUS18514

KEYWORDS botulinum toxin; EC-IC bypass; graft patency; graft occlusion; revascularization; vasospasm

$\mathrm{E}$ ARLY graft occlusion after cerebral revascularization occurs in approximately $5 \%-10 \%$ of cases despite advancements in surgical technique and pharmacological treatments. ${ }^{41,42,53}$ Although rare, graft vasospasm remains a formidable and potentially lethal complication that affects multiple surgical specialties ${ }^{28}$ including plastic and reconstructive surgery, cardiac surgery, and neurosurgery. Patency and spasm rates vary by graft type, with arterial grafts currently preferred for revascularization procedures over venous grafts due to their lower risk of developing intimal hyperplasia and atherosclerosis, and greater long-term patency rates. ${ }^{11}$ Nevertheless, long-term failure of arterial grafts still occurs in $2 \%-18 \%$ of cases, and arterial conduits have a significantly greater risk of vasospasm. Whether from occlusions or flow-limiting vasospasm, perfusion deficits in downstream territories from graft compromise can have devastating clinical consequences. ${ }^{17,25,38}$

Despite extensive study to date, the exact cause of graft vasospasm remains unclear, and there is no single effective spasmolytic agent for preventing graft vasospasm. ${ }^{27,55}$ While complex pharmacological antispastic protocols have been proposed in coronary bypass grafting (often involving systemic vasodilators), their use in cerebrovascular bypass is generally limited by the need to maintain cerebral perfusion in these patients. ${ }^{31}$

Botulinum toxin (BTX) is a potent neurotoxin widely used for the treatment of a variety of spastic and hyperactive autonomic conditions. ${ }^{12,33}$ The potent spasmolytic properties of BTX have sparked interest in its possible application for the prevention of graft spasm. In this review, we examine the current state of knowledge regarding BTX

ABBREVIATIONS BTX = botulinum toxin; $\mathrm{CGRP}=$ calcitonin gene-related peptide; eNOS = endothelial nitric oxide synthase; $\mathrm{KCl}=$ potassium chloride; $\mathrm{MLC}=$ myosin light chain; MLCP = MLC phosphatase; MYPT1 = myosin phosphatase targeting subunit 1; NE = norepinephrine; NO = nitric oxide; RhoA = ras homolog gene family member A; ROCK = rho-associated protein kinase; SNAP = synaptosomal-associated protein; VEGF = vascular endothelial growth factor; VSMC = vascular smooth-muscle cell. SUBMITTED September 29, 2018. ACCEPTED November 7, 2018. INCLUDE WHEN CITING DOI: 10.3171/2018.11.FOCUS18514. 


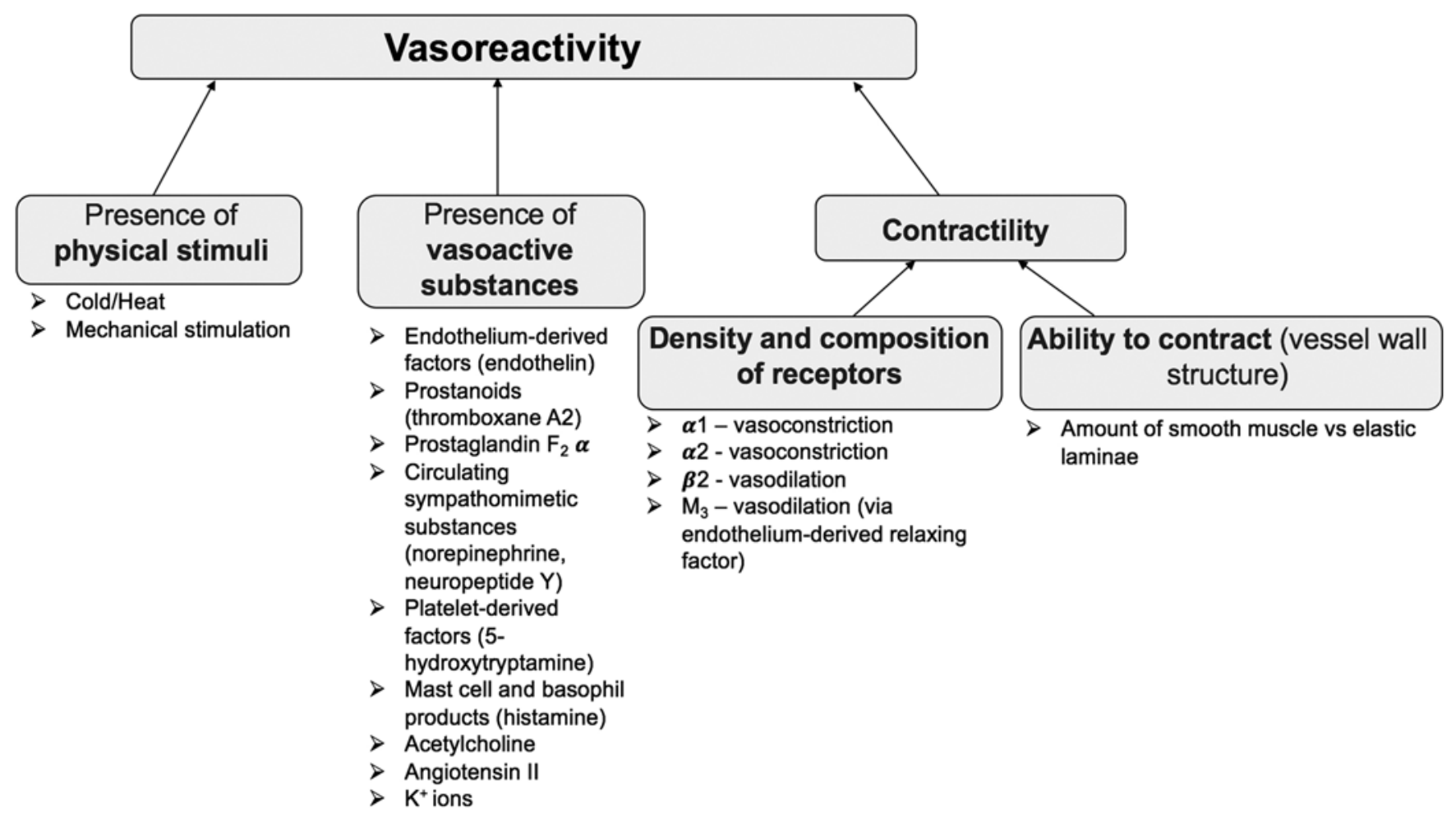

FIG. 1. Factors involved in vasoreactivity. Vasoreactivity is determined not only by external/systemic factors (presence of physical stimuli and vasoactive substances), but also by intrinsic anatomical and physiological contractile properties of blood vessels as dictated by the density and composition of receptors and vessel wall structure.

as it relates to graft vasospasm prevention, with a focus on revascularization conduit anatomy, physiology, and vasomotor mechanistic pathways.

\section{Background}

\section{Graft Vasospasm and Current Treatment Options}

Multiple factors affect vessel wall contractility and must be considered during graft selection and evaluation/ optimization of potential spasmolytic agents. In addition to physical and chemical stimuli, vessel contractility is determined by anatomical features such as wall structure and the density and composition of receptors (Fig. 1), both of which can be affected by patient age and comorbidities such as atherosclerosis, hypertension, and diabetes..$^{25,28,30,35,58}$ Although it is known that dynamic changes in blood vessel diameter are mediated by vascular smoothmuscle cells (VSMCs) and vessel elasticity is determined by the amount of elastic laminae in the vessel wall, ${ }^{24,25}$ less is known about vasomotor receptor composition, which is only described in select arteries and may vary within different segments of the same artery. ${ }^{24,25,29,55}$ Despite their higher contractility, the common utilization of limb arteries in cerebrovascular bypass due to their ease of access and harvest makes the development of effective antispastic treatments critical. ${ }^{24,52}$

The extensive research on coronary artery bypass graft spasm possesses mixed relevance for cerebral revascularization..$^{24,27,29,55}$ Given the multifaceted nature of vasospasm, variability of revascularization conduits, and pharmacological agents each targeting different pathways, a common conclusion of this work has been that there is no single ideal spasmolytic agent. Hence, complex spasmolytic protocols with combinations of different vasodilators applied pre-, intra-, and postoperatively, including both systemic and topical applications, have been developed. Besides emphasizing the importance of atraumatic graft harvest, these protocols typically contain papaverine or calcium channel antagonists (e.g., verapamil or nicardipine) and a nitrate (e.g., nitroglycerin)..$^{24,27}$ The utility of these protocols, which emphasize systemic vasodilator therapy, is limited in cerebrovascular bypass patients given the need for blood pressure/cerebral perfusion maintenance in the postoperative period. ${ }^{31,60}$ Additionally, the effects of intraoperative preventive and postoperative salvage vasodilators such as verapamil or papaverine are typically short-lived, and may require repeat interventions with increasing complication risks. ${ }^{7,19,37}$ Addressing these limitations, the ideal therapeutic agent would be safe, longlasting, and quickly and easily applied intraoperatively for spasm prevention rather than treatment.

\section{BTX-A as a Spasmolytic Agent: Classic Concepts}

BTXs are potent biological toxins produced by anaerobic, gram-positive spore-forming bacteria from the Clostridium genus. There are 7 well-known, serotypically different BTXs $(A-G)$ produced by 6 distinct groups 
of clostridia. ${ }^{56}$ The primary BTX mechanism of action is cholinergic neuromuscular transmission blockade through inhibition of the release of acetylcholine from nerve terminals..$^{33,51,56}$ Specifically, BTX binds to a polysialoganglioside receptor on the presynaptic membrane and enters the nerve terminal via receptor-mediated endocytosis. The light chain of the BTX is a metalloproteinase that then cleaves one or more proteins from the soluble $\mathrm{N}$-methylmaleimide sensitive factor attachment protein receptor complex that mediates synaptic vesicle exocytosis. BTX-B, -D, -F, and -G cleave vesicle-associated membrane protein, while BTX-A and -E cleave synaptosomal-associated protein-25 (SNAP-25), and BTX-C cleaves SNAP-25 and syntaxin. ${ }^{33,56}$ Although this BTXmediated cholinergic neural transmission blockade is irreversible, the duration of BTX paralytic activity varies significantly depending on toxin type, dose, species, and type of cholinergic nerve terminals targeted (autonomic or skeletal muscle).$^{51}$ BTX-A, one of the most commonly used subtypes, induces skeletal muscle paralysis that can be detected 2-3 days after injection and typically reaches its maximum at 1-2 weeks. This effect is gradually lost over time as nerve terminals are remodeled, with complete restoration of neural transmission to baseline levels in 3-4 months. ${ }^{51}$

Currently, BTX is FDA approved for a very limited number of spastic conditions, with the majority of the more than 50 reported therapeutic applications being unlabeled, including hemifacial spasm, hyperhidrosis, headache, urinary incontinence, and Raynaud's phenomenon. ${ }^{12}$

\section{BTX-A Utility in Vasospasm Prevention: Relevant Animal Studies}

To date, BTX use has been reported in 6 animal studies evaluating its effects on microvascular anastomosis patency, vessel diameter, and response to vasospastic challenge on in situ blood vessels or grafts (Table 1). . $14,18,34,45,48$ In these studies, rat $(n=5 / 6)$ and rabbit $(n=1 / 6)$ models were used to evaluate various BTX types $(n=3$ BTX-A, $n=2$ BTX-B, and $n=1$ BTX-C), doses (1-1500 IU), application methods (injection, direct application to the vessels in situ or in a tissue bath), and target vessels (femoral, aortic, and posterior auricular) with variable follow-up (30 minutes to 28 days). BTX efficacy was reported in all of these studies, demonstrating its utility for vasospasm prevention. . $^{14,18,34,48}$ Specifically, BTX improved microvascular anastomosis patency rates ${ }^{18,48}$ and counteracted vasospastic challenges from phenylephrine ${ }^{14,34}$ potassium chloride $(\mathrm{KCl}),{ }^{45}$ norepinephrine (NE), ${ }^{45}$ and cold, ${ }^{14,18,34}$ with these effects detectable as early as 30 minutes ${ }^{45}$ after treatment. The spasmolytic potential of BTX in these studies was shown to be dependent on both dose and application time., ${ }^{5,45}$

Multiple reports on the effects of BTX in animal models of free and pedicled cutaneous, myocutaneous, and muscular flaps also support a potentially multifaceted mechanism of action. We identified 15 animal studies to date (Table 2) where the effects of BTX-A $(n=14)$ and BTX-B $(\mathrm{n}=1)$ on flap viability, vasodilation, blood flow, angiogenesis, and inflammation were evaluated., $1,6-8,10,22,32,36,39,40$, $49,50,54,57,62$ In these studies, a rat model was most commonly used $(n=14 / 15)$ and there was significant variability in BTX dose (0.1-20 IU), application method (subdermal, intradermal, subcutaneous, intramuscular or perivascular injection, direct application to the vessels, or tissue bath), treated flaps (random cutaneous, abdominal or dorsal cutaneous, transverse rectus abdominis myocutaneous, cremaster, spinotrapezius, or gastrocnemius muscular), and evaluation time points (5 minutes to 21 days). Better flap survival rates, ${ }^{10,22,32,36,39,50,54,57}$ increased angiogenesis and angiogenic marker expression, ${ }^{36,39,40,49,50,54}$ improved blood flow, ${ }^{54,57}$ vasodilation, $8,39,50,62$ and reduced inflammation and inflammatory marker expression ${ }^{1,6}$ were observed in the BTX treatment groups as compared to controls. Interestingly, BTX-A also improved random cutaneous flap survival in rats after short- and long-term tobacco exposure, demonstrating its potential efficacy for the prevention of reconstructive and revascularization surgery complications in smokers..$^{10,36}$

Although these animal studies provide valuable insights into the potential benefit of BTX in revascularization surgery, marked differences in innervation and response to spasmogens have been demonstrated between human and animal blood vessels. ${ }^{26,28,29}$ The first translational application of BTX-A for cerebrovascular bypass graft spasm prevention in humans was only recently published. ${ }^{63}$

\section{Potential Mechanisms of BTX A-Mediated Vasospasm Prevention \\ BTX and Adrenergic Vascular Innervation}

Understanding the spasmolytic effects of BTX requires a mechanistic understanding of vasoconstriction. Postganglionic sympathetic axons form a plexus at the adventitia-media border in most arteries, arterioles, and veins across animal species, including humans. ${ }^{68,70}$ Norepinephrine (NE), produced in sympathetic nerves, is released from perivascular axon varicosities after sympathetic stimulation and binds to VSMC postsynaptic $\alpha$ and $\beta$ adrenoreceptors. NE-induced VSMC contraction in most major arteries is thought to be primarily mediated by postsynaptic $\alpha_{1}$ adrenoreceptor activation, with variable contribution from $\alpha_{2}$ receptors (Fig. 2), ${ }^{23}$ although the relative contributions of $\alpha_{1}$ and $\alpha_{2}$ adrenoreceptors to vasoconstriction depends on the anatomical location and segment of the vessel. In fact, in limb arteries the $\alpha_{2}$ adrenoreceptor role in vasoconstriction increases when moving proximal to distal, ${ }^{23}$ a finding that, when combined with the predisposition of the distal end of grafts to vasospasm, suggests a potentially important role of $\alpha_{2}$ receptors in this process. 55

The affinity of BTX for cholinergic transmission blockade has been found to be related to the abundance of highaffinity acceptor sites on cholinergic neurons. ${ }^{9}$ Although noncholinergic nerve terminals have a relatively low number of these acceptor sites, BTX can still be taken up via low-affinity sites if its concentration is high enough.,94 Moreover, while BTX-A cleavable SNAP-25 has been found in sympathetic axons innervating guinea pig blood vessels, NE-mediated vascular constriction was shown to be reduced after BTX-A administration with only partial cleavage of SNAP-25. ${ }^{43,44}$ In light of these findings, it was 


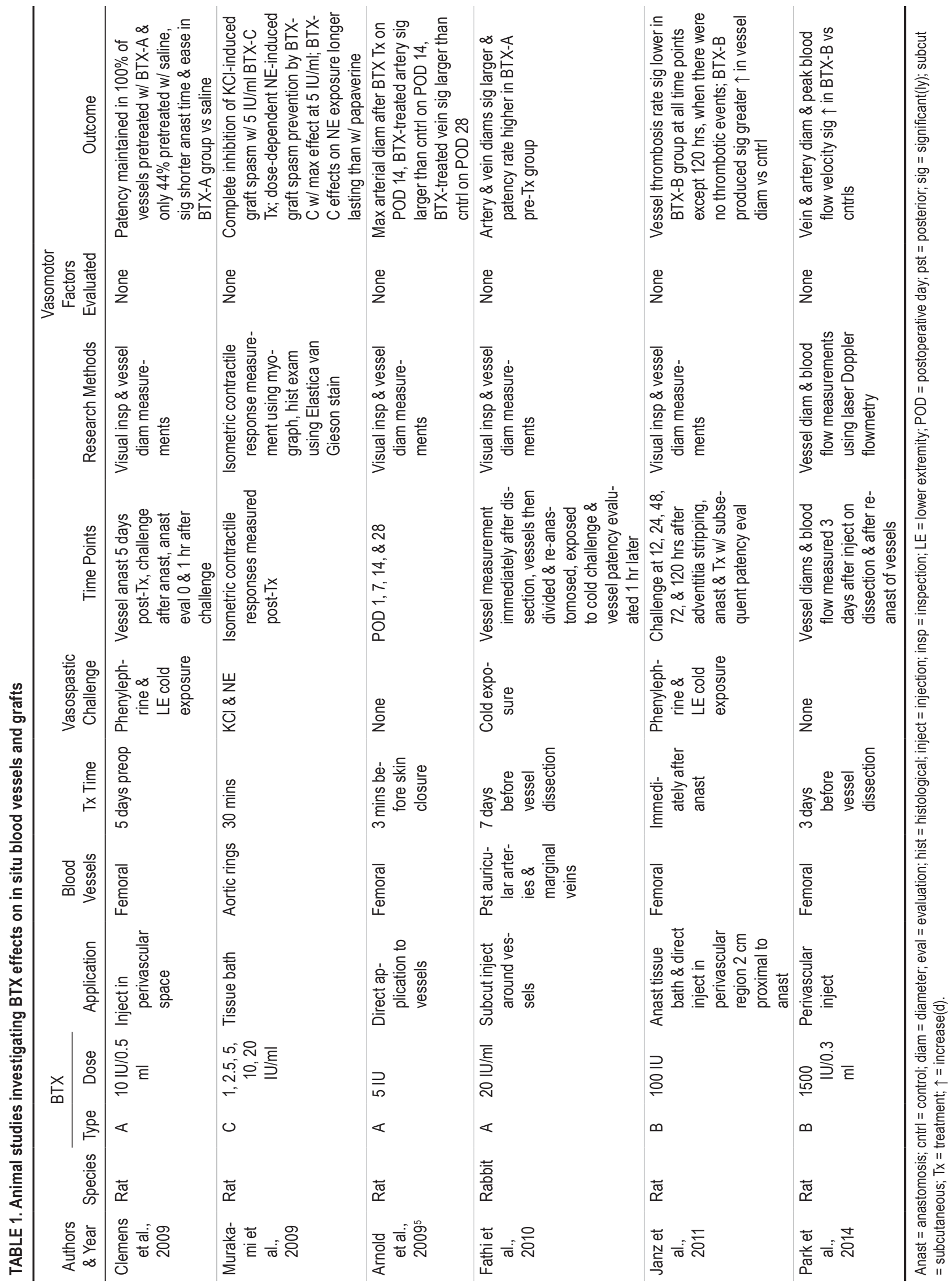




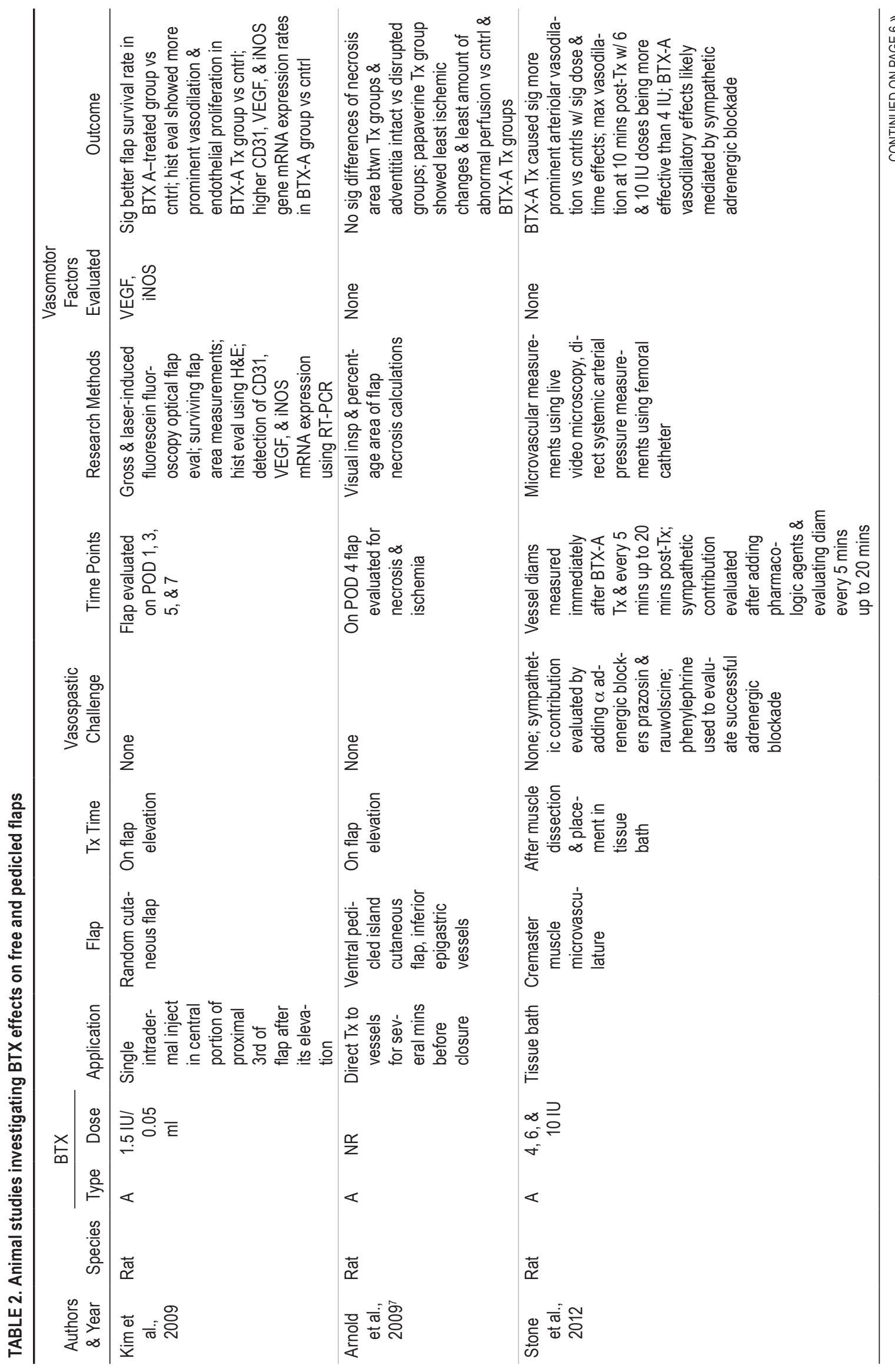




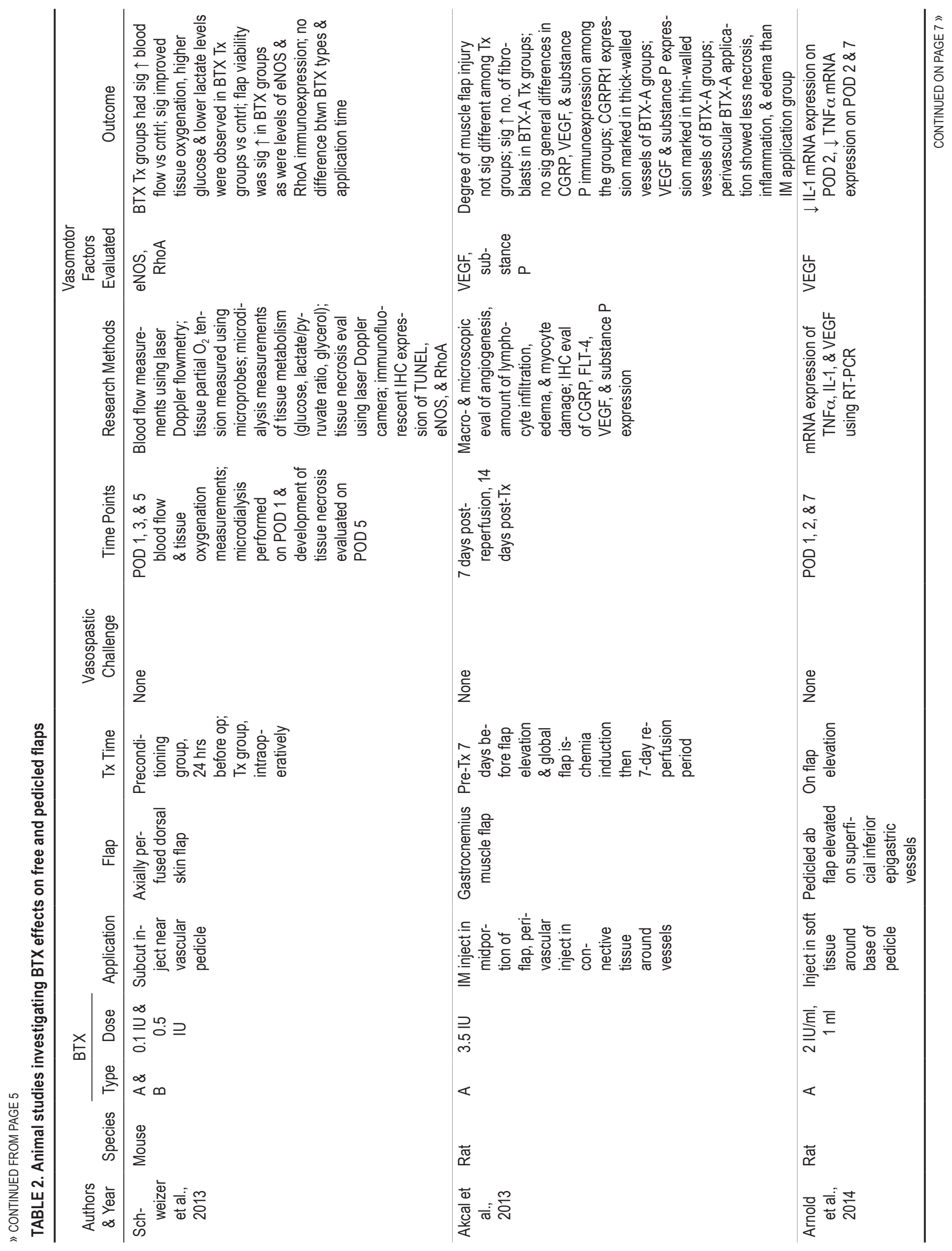




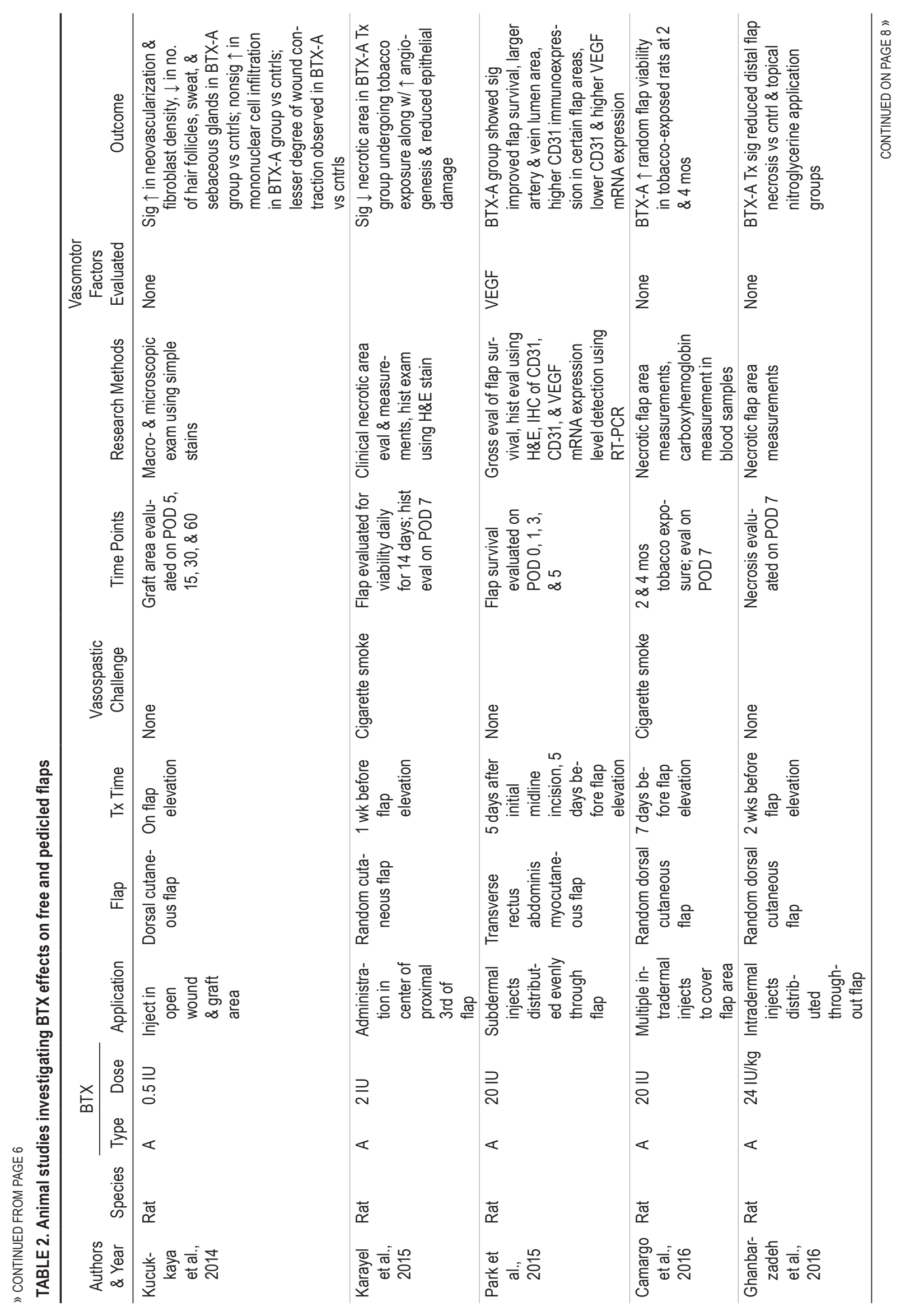




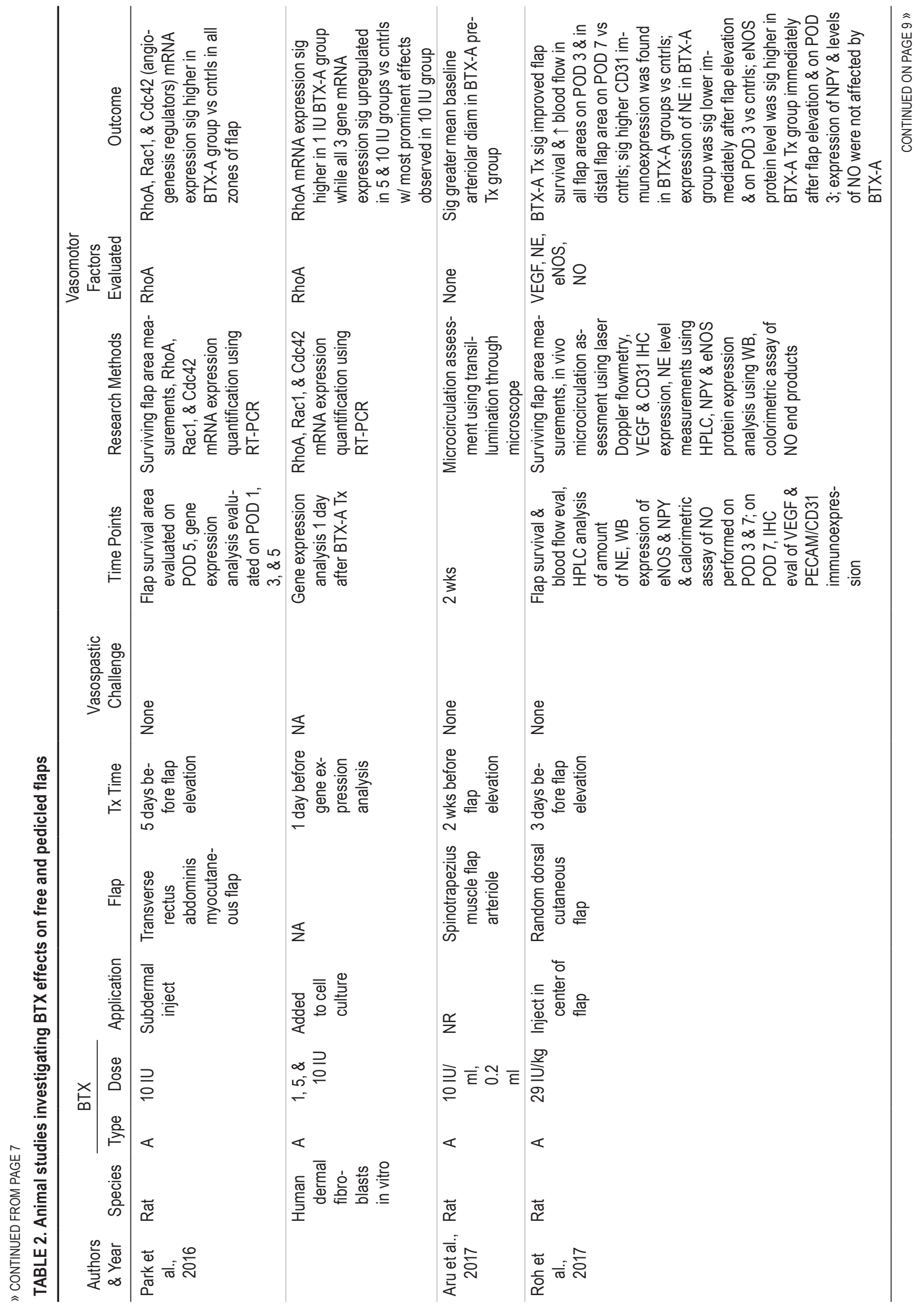




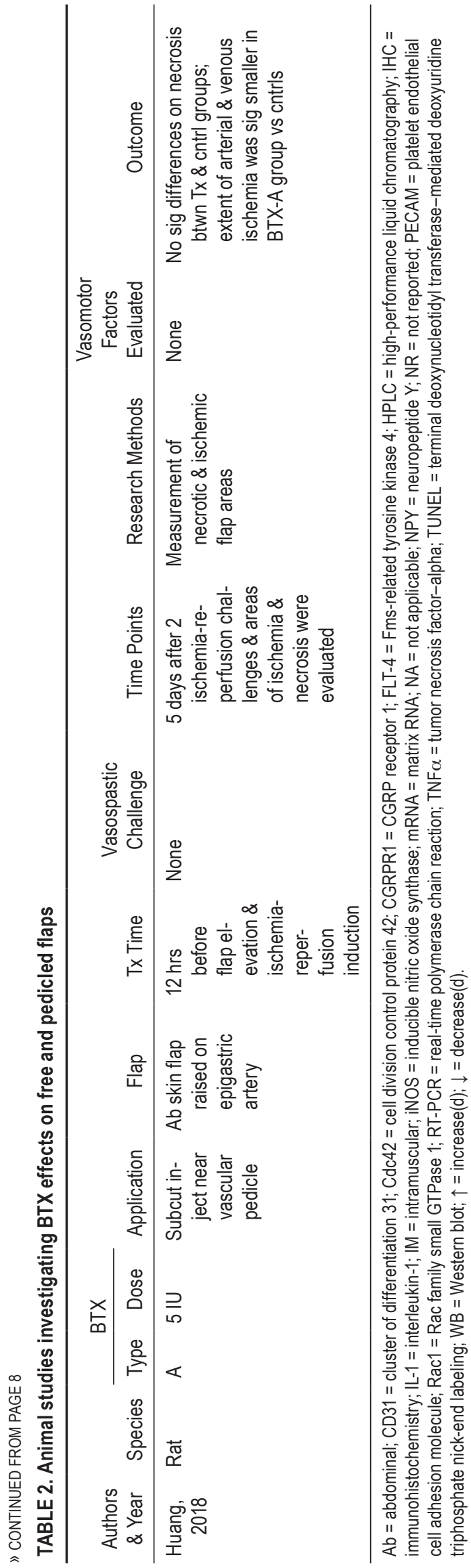

hypothesized that BTX-A might also be inhibiting adrenergic neurotransmission via a mechanism distinct from SNAP-25 cleavage. ${ }^{44}$

A recent study utilized $\alpha_{1}$ and $\alpha_{2}$ receptor blockers to indirectly examine the mechanism of BTX A-mediated vasodilation in rat cremaster muscle microvasculature. ${ }^{62}$ Sympathetic blockade seemed to be the likely mechanism, as BTX-A and adrenergic antagonist administration caused similar levels of vasodilation when applied separately, while BTX application after adrenergic antagonist administration caused no additional vasodilation. Another, more recent study evaluated the effects of BTX-A injection on the survival of random dorsal cutaneous flaps in a rat model,${ }^{54}$ and reported significantly improved flap survival, increased blood flow, and elevated expression of angiogenesis markers and endothelial nitric oxide synthase (eNOS) in the BTX A-treated as compared to the control group. Interestingly, flap tissue NE levels, as measured by highperformance liquid chromatography assay, were found to be significantly reduced immediately and 3 days after flap elevation in the BTX group ( 3 and 6 days after BTX-A treatment, respectively), suggesting that BTX A-mediated blockade of NE release might be contributing to its vasodilatory effects (Fig. 2). Although the reduction of NE found 3 days after BTX-A treatment in this work is likely mediated in part via SNAP-25 cleavage, earlier time points after BTX-A treatment were not investigated, leaving open questions regarding the mechanisms of early BTX-A effects seen when applied to cerebral revascularization and Raynaud's phenomenon (discussed below). Although these studies provide valuable insights into the possible mechanisms of BTX-A vascular spasmolytic activity, they may not be directly translatable to humans given the arterial graft variability and differences in small animal versus human vascular innervation.

\section{Insights From BTX-A Utility in the Treatment of Raynaud's Phenomenon}

Raynaud's phenomenon is characterized by an exaggerated vasospastic response to cold or emotional stress stimuli in cutaneous arterioles. ${ }^{20,46,71}$ The first report of BTXA in patients with Raynaud's phenomenon was published in $2004 .{ }^{64}$ Since then, multiple case series have demonstrated that direct perivascular BTX-A injections can provide rapid and long-lasting digit vasospasm relief. ${ }^{46,47,69}$ Immediate pain relief was reported in more than $80 \%$ of patients, while improved digit perfusion (as evaluated by laser Doppler scans) was achieved within 30 minutes of injection in about $70 \%$ of patients, with a striking $300 \%$ flow improvement as early as 15 minutes after injection. ${ }^{47}$ Notably, the effect of BTX-A in this setting appears to be prolonged, ranging from 13 to 59 months after a single injection. ${ }^{47}$ Direct vasodilatory effects of BTX have also been reported in a rat model as early as 5 minutes after treatment, with a maximum effect seen at 15 minutes. ${ }^{62}$ This differs from classic BTX-A characteristic effects, which have a known delay of several days and a duration of approximately 3-4 months. ${ }^{46,47,51}$ Insights from the current literature on BTX-A indicate that the mechanism of vasospasm prevention is likely different from the classic paradigm. 


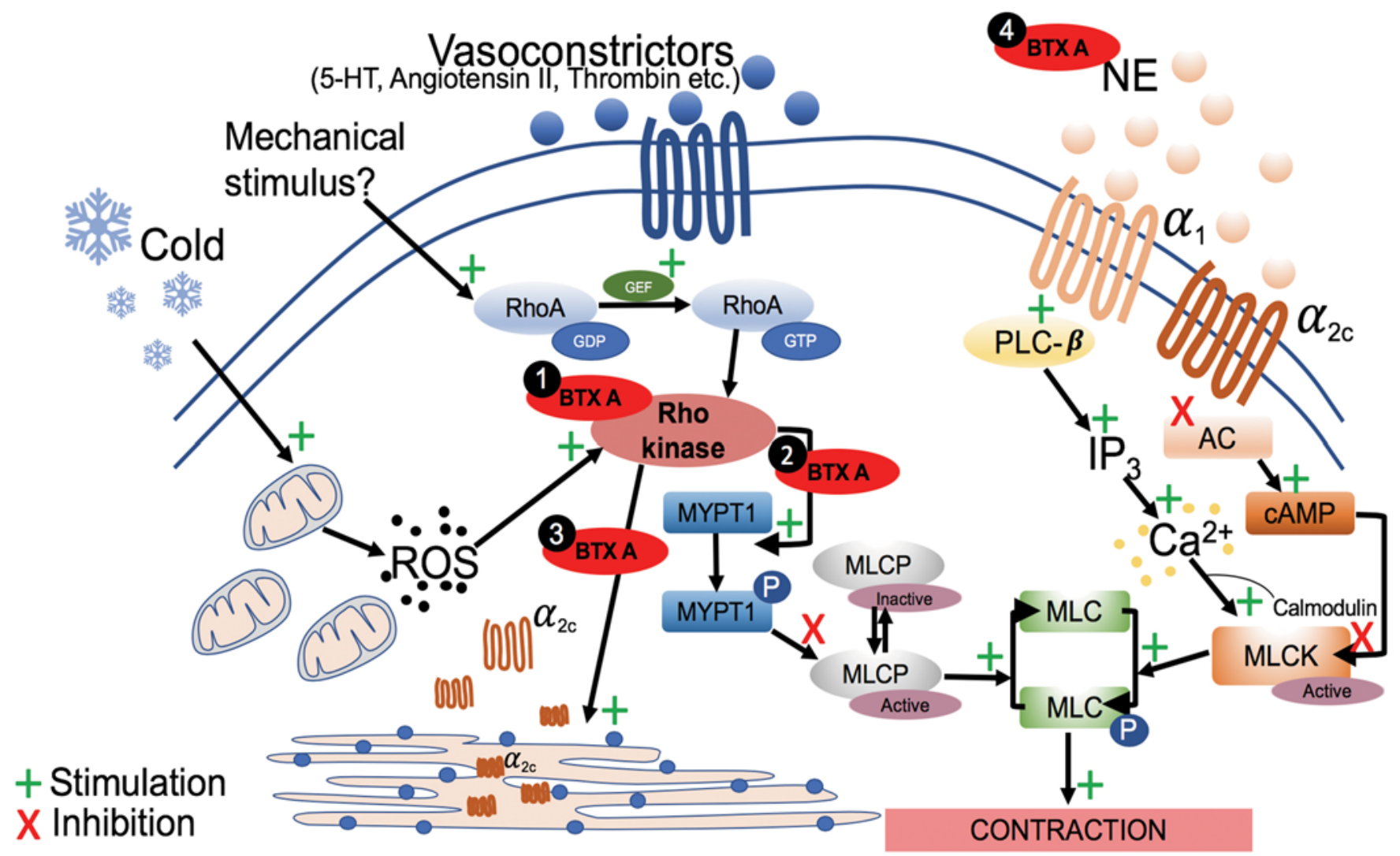

FIG. 2. RhoA/ROCK and adrenergic pathways mediating VSMC contraction. The ROCK pathway is primarily activated by vasoconstrictive substance binding to a $\mathrm{G}$ protein-coupled receptor and activating guanine nucleotide exchange factor (GEF). It can also be activated by reactive oxygen species (ROS) produced by the VSMC mitochondria upon cold exposure or via mechanical stimulus. In the case of cold exposure, activated ROCK promotes $\alpha_{2 c}$ receptor recruitment from the endoplasmic reticulum to the cell membrane. Phosphorylation of the MLC by MLC kinase (MLCK) activated by $\mathrm{Ca}^{2+}$-calmodulin is the main molecular event mediating VSMC contraction. VSMC contraction can also be promoted by MLCP (which mediates MLC dephosphorylation and subsequent inhibition) inactivation by the ROCK downstream effector MYPT1. Adrenergic VSMC contraction occurs via two pathways depending on which receptor is activated. NE binding to the $\alpha_{1}$ receptor activates phospholipase C $\beta$ (PLC $\beta$ ), which increases intracellular $\mathrm{Ca}^{2+}$ levels mediating MLCK activation. NE binding to the $\alpha_{2}$ receptor inhibits adenylyl cyclase (AC), subsequently preventing inactivation of MLCK. BTX A-mediated VSMC relaxation could be mediated via inhibition of the ROCK pathway $(1-3)$, or by blocking release of NE from perivascular adrenergic nerves (4). 5-HT = 5-hydroxytryptamine; cAMP = cyclic adenosine monophosphate; GDP = guanosine diphosphate; GTP = guanosine triphosphate; $\mathrm{IP}_{3}=$ inositol triphosphate.

\section{BTX-A and RhoA/ROCK Pathway}

Growing evidence also demonstrates ras homolog gene family member A (RhoA)/rho-associated protein kinase (ROCK) pathway involvement in not only hypertension pathogenesis via increased inflammation, VSMC contractility, and endothelial dysfunction from negative regulation of the nitric oxide (NO) pathway, ${ }^{16,59,61,72}$ but also in graft vasospasm via similar mechanisms. ${ }^{28}$ Takagi et al. investigated the effects of the ROCK inhibitor fasudil on radial artery graft vasospasm prevention. ${ }^{65}$ Their findings showed an increase of in situ free blood flow with a corresponding decrease of myosin phosphatase targeting subunit 1 (MYPT1) and myosin light chain (MLC) phosphorylation that strongly counteracted the effects of major vasoconstrictors (NE and 5-hydroxytryptamine). Enhanced ROCK activity was also identified in skeletonized, spastic radial arteries as compared to nonmanipulated, nonspastic arteries, indicating that mechanical stimulation-induced vasospasm is likely mediated via the ROCK pathway as well. Moreover, ROCK pathway inhibition via abolished MYPT1 and MLC phosphorylation yielded a greater increase of in situ free blood flow as compared to that produced by the widely used antispastic agent verapamil, which showed no effect on ROCK. ${ }^{65}$ Currently, however, the clinical use of fasudil is approved only in Japan and China.

The two main mechanisms of ROCK-mediated upregulation of VSMC contractility are calcium-dependent translocation of $\alpha_{2 c}$ adrenoreceptors from the Golgi apparatus to the plasma membrane, and inhibition of myosin light chain phosphatase (MLCP; Fig. 2) ${ }^{61}$ Findings from Smith et al. ${ }^{61}$ also demonstrate that ROCK activity (specifically, phosphorylation of MYPT1) and ROCK expression itself can change independently, as MYPT1 phosphorylation activity can increase while ROCK expression remains unchanged in hypertensive as compared to normotensive subjects. This underlines the distinction between ROCK expression and the functionality of its downstream effec- 
tors, and provides a potential explanation for the recent controversial findings of BTX A-mediated Rho kinase upregulation in murine myocutaneous and skin flaps. ${ }^{49,57}$ In these and numerous other animal studies, improved flap survival, increased tissue perfusion, vasodilation, and angiogenesis after BTX-A pretreatment has been demonstrated. 6,8,39,49,57,66 Hence, the reported upregulation of Rho kinase expression in response to BTX-A seems to be contradictory to its well-reported vasodilatory effects in animal models and Raynaud's phenomenon treatments in humans. ${ }^{20,46,64}$ Accordingly, Schweizer et al. hypothesized that increased RhoA immunoexpression after BTX-A administration could result from a compensatory overexpression in response to functional inhibition, ${ }^{77}$ however, no targeted investigations of BTX A-specific effects on RhoA downstream effectors in the ROCK pathway have been reported.

\section{BTX-A and Other Vasoactive Substance Release}

Evidence supporting other mechanistic pathways for BTX-mediated spasmolytic effects has also been reported. Calcitonin gene-related peptide (CGRP) is a known microvascular dilator found in sensory and motor nerve endings, ${ }^{20,67}$ and CGRP upregulation in rat cholinergic nerve terminals and neurons after BTX-mediated muscular paralysis has been found. ${ }^{67}$ Substance $\mathrm{P}$ is a neuropeptide involved in neurogenic inflammation and endothelium-dependent NO-mediated vasodilation. ${ }^{20}$ Although no significant CGRP and substance $\mathrm{P}$ overall immunoexpression differences in BTX A-treated muscular flaps as compared to controls has been demonstrated, prominent CGRP expression was specifically found in thick-walled vessels, while substance $\mathrm{P}$ expression was limited to the thin-walled vessels of BTX A-treated tissues. ${ }^{1}$ Expression of vascular endothelial growth factor (VEGF), a factor in NO-mediated angiogenesis and vasodilation, has also been shown to be increased following BTX administration in multiple animal studies., ${ }^{1,39,50}$ Although more detailed investigation is necessary, these findings indicate that the role of BTX in vasodilation is likely multifactorial.

\section{BTX-A Clinical Use and Safety}

BTX is currently FDA approved for therapeutic and cosmetic indications and has demonstrated an excellent safety profile in labeled as well as unlabeled applications. ${ }^{3,15}$ Serious adverse events such as death, generalized muscle weakness, dysphagia, respiratory insufficiency, and anaphylaxis after BTX injections have been rarely reported and are typically associated with excessively high toxin doses and serious predisposing comorbidities in affected patients. ${ }^{15}$ Generalized side effects have been associated with retrograde axonal migration of BTX from the site of injection..$^{2-4}$ The proposed ex-vivo perivascular toxin application by soaking the graft in a reconstituted BTX-A solution intraoperatively during cerebral bypass does not involve injections. ${ }^{63}$ Moreover, after approximately 30 minutes of soaking in BTX-A solution, the graft is thoroughly flushed and washed to remove any residual toxin, thus minimizing risks of local and systemic spread.
While more extensive studies determining optimal dosing and exposure times for BTX-A use are certainly necessary, the concentration of the toxin proposed in cerebral revascularization grafts is only $10 \mathrm{IU} / \mathrm{ml} .^{63}$ As a comparison, recommended doses of BTX-A used in injection form for spastic disorders reaches up to $100 \mathrm{IU} / \mathrm{ml}$, with total dosages of $360 \mathrm{IU}$ per treatment session. ${ }^{3}$

Similar to numerous currently practiced unlabeled BTX-A and other off-label medication uses, ${ }^{12,13}$ BTX-A use in graft vasospasm is unlabeled and will likely remain so given the costly and time-consuming nature of obtaining FDA approval for new indications of currently approved drugs..$^{21,73}$ Unlabeled drug use, defined as prescribing currently available medications for an indication that does not have FDA approval (including unapproved patient populations, doses, or administration forms) ${ }^{73}$ is nonetheless at the treating physician's discretion for indications that they believe are in the patient's best interests based on credible evidence. $^{21,73}$

\section{Conclusions}

Animal studies suggest that BTX effects on the vasculature likely reach beyond its classic cholinergic paradigm and involve multiple pathways. The optimal application conditions and therapeutic outcomes for BTX use in revascularization patients remain ill defined. Elucidating the role of BTX-A in graft spasm prevention will aid in determining whether and how the findings from animal studies are translated to clinical practice. This knowledge will aid in optimizing patients, conduit selection, and application conditions for BTX treatment. Based on experimental data and initial clinical reports of BTX-A for spasmolysis, the applications for BTX-A will likely extend to cardiac revascularization as well as reconstructive surgery.

\section{References}

1. Akcal A, Sevim KZ, Yesilada A, Kiyak V, Sucu DO, Tatlidede HS, et al: Comparison of perivascular and intramuscular applied botulinum toxin a pretreatment on muscle flap ischemia-reperfusion injury and chemical delay. J Craniofac Surg 24:278-283, 2013

2. Alimohammadi M, Punga AR: Neurophysiological measures of efficacy and safety for botulinum toxin injection in facial and bulbar muscles: special considerations. Toxins (Basel) 9:E352, 2017

3. Alter KE, Wilson NA: Botulinum Neurotoxin Injection Manual. New York: Demos Medical Publishing, 2015

4. Antonucci F, Rossi C, Gianfranceschi L, Rossetto O, Caleo M: Long-distance retrograde effects of botulinum neurotoxin A. J Neurosci 28:3689-3696, 2008

5. Arnold PB, Campbell CA, Rodeheaver G, Merritt W, Morgan RF, Drake DB: Modification of blood vessel diameter following perivascular application of botulinum toxin-A. Hand $(\mathbf{N}$ Y) 4:302-307, 2009

6. Arnold PB, Fang T, Songcharoen SJ, Ziakas G, Zhang F: Inflammatory response and survival of pedicled abdominal flaps in a rat model after perivascular application of botulinum toxin type A. Plast Reconstr Surg 133:491e-498e, 2014

7. Arnold PB, Merritt W, Rodeheaver GT, Campbell CA, Morgan RF, Drake DB: Effects of perivascular botulinum toxinA application on vascular smooth muscle and flap viability in the rat. Ann Plast Surg 62:463-467, 2009 
8. Aru RG, Songcharoen SJ, Seals SR, Arnold PB, Hester RL: Microcirculatory effects of botulinum toxin A in the rat: acute and chronic vasodilation. Ann Plast Surg 79:82-85, 2017

9. Black JD, Dolly JO: Selective location of acceptors for botulinum neurotoxin A in the central and peripheral nervous systems. Neuroscience 23:767-779, 1987

10. Camargo CP, Fernandes FA, Lee MH, Silva LC, Besteiro JM, Gemperli R: The positive effect of Botulinum toxin type A on the viability of random flap in tobacco exposed in rats. Acta Cir Bras 31:720-723, 2016

11. Carrel T, Winkler B: Current trends in selection of conduits for coronary artery bypass grafting. Gen Thorac Cardiovasc Surg 65:549-556, 2017

12. Cheng CM, Chen JS, Patel RP: Unlabeled uses of botulinum toxins: a review, part 1. Am J Health Syst Pharm 63:145152,2006

13. Cheng CM, Chen JS, Patel RP: Unlabeled uses of botulinum toxins: a review, part 2. Am J Health Syst Pharm 63:225232, 2006

14. Clemens MW, Higgins JP, Wilgis EF: Prevention of anastomotic thrombosis by botulinum toxin a in an animal model. Plast Reconstr Surg 123:64-70, 2009

15. Coté TR, Mohan AK, Polder JA, Walton MK, Braun MM: Botulinum toxin type A injections: adverse events reported to the US Food and Drug Administration in therapeutic and cosmetic cases. J Am Acad Dermatol 53:407-415, 2005

16. Dong M, Yan BP, Liao JK, Lam YY, Yip GW, Yu CM: Rhokinase inhibition: a novel therapeutic target for the treatment of cardiovascular diseases. Drug Discov Today 15:622-629, 2010

17. Fabbrocini M, Fattouch K, Camporini G, DeMicheli G, Bertucci C, Cioffi P, et al: The descending branch of lateral femoral circumflex artery in arterial CABG: early and midterm results. Ann Thorac Surg 75:1836-1841, 2003

18. Fathi M, Fathi H, Mazloumi M, Khalilzadeh O, Amanpour S, Meysamie A, et al: Preventive effect of botulinum toxin A in microanastomotic thrombosis: a rabbit model. J Plast Reconstr Aesthet Surg 63:e720-e724, 2010

19. Feng L, Fitzsimmons BF, Young WL, Berman MF, Lin E, Aagaard BD, et al: Intraarterially administered verapamil as adjunct therapy for cerebral vasospasm: safety and 2-year experience. AJNR Am J Neuroradiol 23:1284-1290, 2002

20. Fonseca C, Abraham D, Ponticos M: Neuronal regulators and vascular dysfunction in Raynaud's phenomenon and systemic sclerosis. Curr Vasc Pharmacol 7:34-39, 2009

21. França K, Litewka S: Controversies in off-label prescriptions in dermatology: the perspective of the patient, the physician, and the pharmaceutical companies. Int J Dermatol [epub ahead of print], 2018

22. Ghanbarzadeh K, Tabatabaie OR, Salehifar E, Amanlou M, Khorasani G: Effect of botulinum toxin A and nitroglycerin on random skin flap survival in rats. Plast Surg (Oakv) 24:99-102, 2016

23. Guimarães S, Moura D: Vascular adrenoceptors: an update. Pharmacol Rev 53:319-356, 2001

24. He GW: Arterial grafts: clinical classification and pharmacological management. Ann Cardiothorac Surg 2:507-518, 2013

25. He GW: Arterial grafts for coronary artery bypass grafting: biological characteristics, functional classification, and clinical choice. Ann Thorac Surg 67:277-284, 1999

26. He GW, Rosenfeldt FL, Buxton BF, Angus JA: Reactivity of human isolated internal mammary artery to constrictor and dilator agents. Implications for treatment of internal mammary artery spasm. Circulation 80:I141-I150, 1989

27. He GW, Taggart DP: Antispastic management in arterial grafts in coronary artery bypass grafting surgery. Ann Thorac Surg 102:659-668, 2016
28. He GW, Taggart DP: Spasm in arterial grafts in coronary artery bypass grafting surgery. Ann Thorac Surg 101:12221229,2016

29. He GW, Yang CQ: Characteristics of adrenoceptors in the human radial artery: clinical implications. J Thorac Cardiovasc Surg 115:1136-1141, 1998

30. He GW, Yang CQ: Radial artery has higher receptor-mediated contractility but similar endothelial function compared with mammary artery. Ann Thorac Surg 63:1346-1352, 1997

31. Heiferman DM, Souter JR, Reynolds MR, Anderson DE, Serrone JC: Extracranial-to-intracranial bypass for pressor dependent cerebrovascular insufficiency: modified classification and representative case. Curr Neurovasc Res 15:256-261, 2018

32. Huang L: Beneficial effect of botulinum toxin A on secondary ischaemic injury of skin flaps in rats. Br J Oral Maxillofac Surg 56:144-147, 2018

33. Jankovic J: Botulinum toxin: state of the art. Mov Disord 32:1131-1138, 2017

34. Janz BA, Thomas PR, Fanua SP, Dunn RE, Wilgis EF, Means KR Jr: Prevention of anastomotic thrombosis by botulinum toxin B after acute injury in a rat model. J Hand Surg Am 36:1585-1591, 2011

35. Joyner MJ, Dietz NM: Sympathetic vasodilation in human muscle. Acta Physiol Scand 177:329-336, 2003

36. Karayel H, Kaya B, Caydere M, Terzioğlu A, Aslan G: Prevention of unfavourable effects of cigarette smoke on flap viability using botulinum toxin in random pattern flaps: an experimental study. Plast Surg (Oakv) 23:177-182, 2015

37. Keyrouz SG, Diringer MN: Clinical review: Prevention and therapy of vasospasm in subarachnoid hemorrhage. Crit Care 11:220, 2007

38. Khot UN, Friedman DT, Pettersson G, Smedira NG, Li J, Ellis SG: Radial artery bypass grafts have an increased occurrence of angiographically severe stenosis and occlusion compared with left internal mammary arteries and saphenous vein grafts. Circulation 109:2086-2091, 2004

39. Kim TK, Oh EJ, Chung JY, Park JW, Cho BC, Chung HY: The effects of botulinum toxin A on the survival of a random cutaneous flap. J Plast Reconstr Aesthet Surg 62:906-913, 2009

40. Kucukkaya D, Irkoren S, Ozkan S, Sivrioglu N: The effects of botulinum toxin A on the wound and skin graft contraction. J Craniofac Surg 25:1908-1911, 2014

41. Lawton MT, Hamilton MG, Morcos JJ, Spetzler RF: Revascularization and aneurysm surgery: current techniques, indications, and outcome. Neurosurgery 38:83-94, 1996

42. Liu JK, Kan P, Karwande SV, Couldwell WT: Conduits for cerebrovascular bypass and lessons learned from the cardiovascular experience. Neurosurg Focus 14(3):e3, 2003

43. Morris JL, Jobling P, Gibbins IL: Botulinum neurotoxin A attenuates release of norepinephrine but not NPY from vasoconstrictor neurons. Am J Physiol Heart Circ Physiol 283:H2627-H2635, 2002

44. Morris JL, Jobling P, Gibbins IL: Differential inhibition by botulinum neurotoxin A of cotransmitters released from autonomic vasodilator neurons. Am J Physiol Heart Circ Physiol 281:H2124-H2132, 2001

45. Murakami E, Iwata H, Imaizumi M, Takemura H: Prevention of arterial graft spasm by botulinum toxin: an in-vitro experiment. Interact Cardiovasc Thorac Surg 9:395-398, 2009

46. Neumeister MW: The role of botulinum toxin in vasospastic disorders of the hand. Hand Clin 31:23-37, 2015

47. Neumeister MW, Chambers CB, Herron MS, Webb K, Wietfeldt J, Gillespie JN, et al: Botox therapy for ischemic digits. Plast Reconstr Surg 124:191-201, 2009

48. Park BY, Kim HK, Kim WS, Bae TH: The effect of botulinum toxin B pretreatment to the blood flow in the microvascular anastomosis. Ann Plast Surg 72:214-219, 2014 
49. Park TH, Park JH, Chang CH, Rah DK: Botulinum toxin A upregulates Rac1, Cdc42, and RhoA gene expression in a dose-dependent manner: in vivo and in vitro study. J Craniofac Surg 27:516-520, 2016

50. Park TH, Rah DK, Chong Y, Kim JK: The effects of botulinum toxin A on survival of rat TRAM flap with vertical midline scar. Ann Plast Surg 74:100-106, 2015

51. Pirazzini M, Rossetto O, Eleopra R, Montecucco C: Botulinum neurotoxins: biology, pharmacology, and toxicology. Pharmacol Rev 69:200-235, 2017

52. Ramanathan D, Starnes B, Hatsukami T, Kim LJ, Di Maio S, Sekhar L: Tibial artery autografts: alternative conduits for high flow cerebral revascularizations. World Neurosurg 80:322-327, 2013

53. Roh SW, Ahn JS, Sung HY, Jung YJ, Kwun BD, Kim CJ: Extracranial-intracranial bypass surgery using a radial artery interposition graft for cerebrovascular diseases. J Korean Neurosurg Soc 50:185-190, 2011

54. Roh TS, Jung BK, Yun I, Lew DH, Kim YS: Effect of botulinum toxin A on vasoconstriction and sympathetic neurotransmitters in a murine random pattern skin flap model. Wound Repair Regen 25:75-85, 2017

55. Rosenfeldt FL, He GW, Buxton BF, Angus JA: Pharmacology of coronary artery bypass grafts. Ann Thorac Surg 67:878888,1999

56. Rossetto O, Pirazzini M, Montecucco C: Botulinum neurotoxins: genetic, structural and mechanistic insights. Nat Rev Microbiol 12:535-549, 2014

57. Schweizer DF, Schweizer R, Zhang S, Kamat P, Contaldo C, Rieben $\mathrm{R}$, et al: Botulinum toxin $\mathrm{A}$ and $\mathrm{B}$ raise blood flow and increase survival of critically ischemic skin flaps. J Surg Res 184:1205-1213, 2013

58. Shapira OM, Xu A, Aldea GS, Vita JA, Shemin RJ, Keaney JF Jr: Enhanced nitric oxide-mediated vascular relaxation in radial artery compared with internal mammary artery or saphenous vein. Circulation 100 (19 Suppl):II322-II327, 1999

59. Shimokawa H, Sunamura S, Satoh K: RhoA/Rho-kinase in the cardiovascular system. Circ Res 118:352-366, 2016

60. Sia SF, Qian Y, Zhang Y, Morgan MK: Mean arterial pressure required for maintaining patency of extracranial-to-intracranial bypass grafts: an investigation with computational hemodynamic models - case series. Neurosurgery 71:826831,2012

61. Smith CJ, Santhanam L, Alexander LM: Rho-kinase activity and cutaneous vasoconstriction is upregulated in essential hypertensive humans. Microvasc Res 87:58-64, 2013

62. Stone AV, Koman LA, Callahan MF, Eckman DM, Smith BP, Plate JF, et al: The effect of botulinum neurotoxin-A on blood flow in rats: a potential mechanism for treatment of Raynaud phenomenon. J Hand Surg Am 37:795-802, 2012

63. Strickland BA, Rennert RC, Bakhsheshian J, Bulic S, Correa AJ, Amar A, et al: Botulinum toxin to improve vessel graft patency in cerebral revascularization surgery: report of 3 cases. J Neurosurg [epub ahead of print March 2, 2018. DOI: $10.3171 / 2017.9 . J N S 171292]$
64. Sycha T, Graninger M, Auff E, Schnider P: Botulinum toxin in the treatment of Raynaud's phenomenon: a pilot study. Eur J Clin Invest 34:312-313, 2004

65. Takagi T, Okamoto Y, Tomita S, Sato A, Yamaguchi S, Takuwa Y, et al: Intraradial administration of fasudil inhibits augmented Rho kinase activity to effectively dilate the spastic radial artery during coronary artery bypass grafting surgery. J Thorac Cardiovasc Surg 142:e59-e65, 2011

66. Tang Q, Chen C, Wang X, Li W, Zhang Y, Wang M, et al: Botulinum toxin A improves adipose tissue engraftment by promoting cell proliferation, adipogenesis and angiogenesis. Int J Mol Med 40:713-720, 2017

67. Tarabal O, Calderó J, Ribera J, Sorribas A, López R, Molgó $\mathrm{J}$, et al: Regulation of motoneuronal calcitonin gene-related peptide (CGRP) during axonal growth and neuromuscular synaptic plasticity induced by botulinum toxin in rats. Eur J Neurosci 8:829-836, 1996

68. Thomas GD: Neural control of the circulation. Adv Physiol Educ 35:28-32, 2011

69. Van Beek AL, Lim PK, Gear AJ, Pritzker MR: Management of vasospastic disorders with botulinum toxin A. Plast Reconstr Surg 119:217-226, 2007

70. Westcott EB, Segal SS: Perivascular innervation: a multiplicity of roles in vasomotor control and myoendothelial signaling. Microcirculation 20:217-238, 2013

71. Wigley FM, Flavahan NA: Raynaud's phenomenon. N Engl J Med 375:556-565, 2016

72. Wirth A: Rho kinase and hypertension. Biochim Biophys Acta 1802:1276-1284, 2010

73. Wittich CM, Burkle CM, Lanier WL: Ten common questions (and their answers) about off-label drug use. Mayo Clin Proc 87:982-990, 2012

\section{Disclosures}

The authors report no conflict of interest concerning the materials or methods used in this study or the findings specified in this paper.

\section{Author Contributions}

Conception and design: all authors. Acquisition of data: Russin, Ravina, Carey. Analysis and interpretation of data: all authors. Drafting the article: Russin, Ravina, Rennert. Critically revising the article: Russin, Ravina, Strickland. Reviewed submitted version of manuscript: all authors. Administrative/technical/material support: Russin, Carey. Study supervision: Russin.

\section{Correspondence}

Jonathan J. Russin: University of Southern California Neurorestoration Center, The Keck School of Medicine, Los Angeles, CA. jonathan.russin@med.usc.edu. 